\title{
Influence of DE3 tide on the equinoctial asymmetry of the zonal mean ionospheric electron density
}

\author{
Zhipeng Ren ${ }^{1,2^{*}}$, Weixing Wan ${ }^{1,2}$, Jiangang Xiong ${ }^{1,2}$ and Libo Liu ${ }^{1,2}$
}

\begin{abstract}
Through respectively adding September DE3 tide and March DE3 tide at the low boundary of Global Coupled Ionosphere-Thermosphere-Electrodynamics Model, Institute of Geology and Geophysics, Chinese Academy of Sciences (GCITEM-IGGCAS), we simulate the influence of DE3 tide on the equinoctial asymmetry of the zonal mean ionospheric electron density. The influence of DE3 tide on the equinoctial asymmetry of the zonal mean electron density varies with latitude, altitude, and solar activity level. Compared with the density driven by the September DE3 tide, the March DE3 tide mainly decreases the lower ionospheric zonal mean electron density and mainly increases the electron density at higher ionosphere. In the low-latitude ionosphere, DE3 tide drives an equatorial ionization anomaly (EIA) structure at higher ionosphere in the relative difference of zonal mean electron density, which suggests that DE3 tide affects the longitudinal mean equatorial vertical $E \times B$ plasma drifts. Although the lower ionospheric equinoctial asymmetry driven by DE3 tide mainly decreases with the increase of solar activity, the asymmetry at higher ionosphere mainly increases with solar activity. However, EIA in equinoctial asymmetry mainly decreases with the increase of solar activity.
\end{abstract}

Keywords: Ionospheric equinoctial asymmetry; DE3 tide; lonosphere-atmosphere coupling

\section{Findings}

\section{Introduction}

The ionospheric seasonal variability is an unresolved important question in ionospheric research. The previous works are mainly focused on the differences between summer and winter and between solstice and equinox (e.g., Zhao et al. 2007). However, since Titheridge (1973) first studied the difference between the mid-latitude ionospheric electron density in March equinox and that in September equinox, many researchers paid attention to the ionospheric equinoctial asymmetry (e.g., Liu et al. 2010). Now, the ionospheric equinoctial asymmetry, with some ionospheric parameters being larger during one equinox than those during the other one, is an important feature of ionospheric seasonal variation, and the equinoctial asymmetry had been found in a series of ionospheric

\footnotetext{
* Correspondence: zpren@mail.iggcas.ac.cn

'Key Laboratory of Earth and Planetary Physics, Institute of Geology and Geophysics, Chinese Academy of Sciences, Beijing 100029, China

${ }^{2}$ Beijing National Observatory of Space Environment, Institute of Geology and Geophysics, Chinese Academy of Sciences, Beijing 100029, China
}

parameters, such as total electron content (TEC), topside ionospheric electron density, ionospheric electron density profiles, the $\mathrm{F}$ layer height, electron temperatures, ion temperatures, field-parallel drifts, and field-perpendicular plasma drifts (e.g., Titheridge and Buonsanto 1983; Aruliah et al. 1996; Balan et al. 1998, 2006; Bailey et al. 2000; Kawamura et al. 2002; Unnikrishnan et al. 2002; Zhang et al. 2004; Zhao et al. 2007; Wan et al. 2008; Ren et al. 2011a).

Although the earlier researchers are mainly focused on the ionospheric equinoctial asymmetry in the high- and mid-latitude, recent research suggested that the lowlatitude ionospheric equinoctial asymmetry is also important. Liu et al. (2010) investigated the daytime ionospheric behaviors around equinoxes and found that the equinoctial asymmetry in the ionospheric plasma density during low solar activity is mainly a low-latitude phenomenon. Chen et al. (2012) studied the equinoctial asymmetry in solar activity variations of NmF2 and TEC. With vertical drift $\left(\mathrm{V}_{\perp}\right)$ data observed by ROCSAT-1, Ren et al. (2011a) studied the equinoctial asymmetry of equatorial $V_{\perp}$ and suggested 
that such asymmetry can partly explain the equinoctial asymmetry in daytime low-latitude ionospheric plasma density observed by Liu et al. (2010). Based on the average values of ionosonde hmF2 data acquired from an African equatorial station, Adebesin et al. (2013) also found the equinoctial asymmetry in equatorial $\mathrm{V}_{\perp}$. Using multiinstrument observations, Sripathi et al. (2011) studied equinoctial asymmetry in the equatorial spread F (ESF) irregularities over Indian region. Based on the observations using FORMOSAT-3/COSMIC GPS RO technique during a solar minimum year, Brahmanandam et al. (2012) observed the equinoctial asymmetry in the global S4 index. They both suggested that the equinoctial asymmetry in equatorial $\mathrm{V}_{\perp}$ plays an important role in the generation of these asymmetries. Ren et al. (2012a) simulated the influence of atmospheric tides on equinoctial asymmetry of $\mathrm{V}_{\perp}$ with TIDM-IGGCAS-II ionospheric dynamo model (Ren et al. 2008) and found that the simulated equinoctial asymmetry in $\mathrm{V}_{\perp}$ are mainly driven by the migrating diurnal tide, the migrating semidiurnal tide, the eastward propagating non-migrating diurnal tide with zonal wave number 2 (DE2), and the eastward propagating nonmigrating diurnal tide with zonal wave number 3 (DE3).

DE3 is excited in the tropical troposphere, propagates vertically, and is sometimes the single largest tidal component above the mesopause (Forbes et al. 2008; Oberheide and Forbes 2008; Mukhtarov et al. 2009; Pancheva and Mukhtarov 2010). There are growing observational evidences that DE3 is one of the main sources of the longitudinal wavenumber-4 structure (WN4) in the ionosphere. Although some observational and numerical simulation evidences indicate that not only DE3 tide but also SPW4 and SE2 waves have contribution to the ionospheric WN4, DE3 still attracts a considerable attention. Based on the satellite observations, Oberheide and Forbes (2008), Ren et al. (2009a, 2010), and Wan et al. (2010) all found that the zonal wind of DE3 is stronger and occurs primarily during northern summer and autumn and DE3 tide shows obvious equinoctial asymmetry. In the previous research, many researchers simulated the influence of DE3 tide on ionosphere (e.g., Ren et al. 2011b, 2012b; Wan et al. 2012; Wu et al. 2012). However, most of these work mainly paid attention to the coupling between DE3 and the ionospheric WN4. For example, Jin et al. (2008) and Ren et al. (2010) mainly simulated the influence of DE3 tide on the WN4 structure in equatorial vertical $\mathrm{E} \times \mathrm{B}$ plasma drifts.

DE3 tide not only drives the ionospheric WN4 structures but also affects the mean states of ionosphere and thermosphere. Forbes et al. (1993) utilized NCAR TIGCM to simulate tidal influence on ionosphere and thermosphere and found that the upward propagating migrating tides can accelerate, heat, and mix composition in the coupled ionosphere-thermosphere system. Jones et al. (2014) simulated the impacts of vertically propagating tides on the mean state of the ionosphere and thermosphere and found that the non-migrating tide DE3 also can affect the ionospheric mean state. Because the intra-annual variation of DE3 tide shows equinoctial asymmetry, DE3 tide may also affect the equinoctial asymmetry of the ionospheric mean states. Not only DE3 tide but also the migrating diurnal and semidiurnal tides show obvious equinoctial asymmetry and may affect the ionospheric equinoctial asymmetry (see Forbes et al. 1993, Mukhtarov et al. 2009, and Jones et al. 2014). However, because of the nonlinearly interaction and nonlinearly interaction between different tides, the tides' influences on ionospheric equinoctial asymmetry are very complex. Hence, in this paper, we will mainly pay attention to the influence of DE3 tide and simulate the influence of DE3 tide on the equinoctial asymmetry of the ionospheric zonal mean states with Global Coupled Ionosphere-Thermosphere-Electrodynamics Model, Institute of Geology and Geophysics, Chinese Academy of Sciences (GCITEM-IGGCAS) and Three-Dimensional Theoretical Ionospheric Model of the Earth, Institute of Geology and Geophysics, Chinese Academy of Sciences (TIME3D-IGGCAS).

\section{Model descriptions and inputs}

To simulate the complex and highly coupled physical and chemical processes in the ionosphere-thermosphere system, we had developed a global coupled ionospherethermosphere model (GCITEM-IGGCAS). GCITEMIGGCAS is a three-dimensional (3-D) code with $5^{\circ}$ latitude by $7.5^{\circ}$ longitude cells in a spherical geographical coordinate system, which bases on an altitude grid. This model self-consistently calculates the time-dependent 3-D structures of the main thermospheric and ionospheric parameters in the height range from 90 to $600 \mathrm{~km}$, including the neutral number density of major species $\mathrm{O}_{2}, \mathrm{~N}_{2}$, and $\mathrm{O}$ and minor species $\mathrm{N}\left({ }^{2} \mathrm{D}\right), \mathrm{N}\left({ }^{4} \mathrm{~S}\right), \mathrm{NO}, \mathrm{He}$, and $\mathrm{H}$; ion number densities of $\mathrm{O}^{+}, \mathrm{O}_{2}{ }^{+}, \mathrm{N}_{2}{ }^{+}, \mathrm{NO}^{+}, \mathrm{N}^{+}$, and electrons; neutral, electron, and ion temperatures; neutral wind vectors; and ionospheric electric field. GCITEM-IGGCAS can reproduce the main features of the thermosphere and ionosphere. The details of GCITEM-IGGCAS are given in Ren et al. (2009b).

Because it uses a spherical geographical coordinate system, GCITEM-IGGCAS could not self-consistently calculate the heat flux and plasma flux at the upper boundary and had to obtain these fluxes from empirical models. Theoretical ionospheric model based on the closed geomagnetic tubes can self-consistently calculate these fluxes. TIME3D-IGGCAS is a three-dimensional theoretical ionospheric model in realistic geomagnetic fields (Ren et al. 2012c). This model covers the whole ionosphere and whole plasmasphere and can self-consistently calculate the time-dependent three-dimensional structures of the main 
ionospheric and plasmaspheric parameters in realistic geomagnetic fields, including ion number densities of $\mathrm{O}^{+}$, $\mathrm{H}^{+}, \mathrm{He}^{+}, \mathrm{NO}^{+}, \mathrm{O}_{2}^{+}, \mathrm{N}_{2}^{+}$, and electron; electron and ion temperature; and ion velocity vectors. TIME3D-IGGCAS and GCITEM-IGGCAS can two-way couple with each other. In this condition, GCITEM-IGGCAS will close its ionosphere module and run TIME3D-IGGCAS as its ionosphere-plasmasphere module. TIME3D-IGGCAS will obtain the self-consistent calculated neutral composition, neutral density, neutral winds, and mid- and low-latitude ionospheric electric fields from GCITEM-IGGCAS model and provide the self-consistent calculated ion composition, ion and electron densities, ion and electron temperatures, and ion velocity vectors in the mid- and low-latitude ionospheres to GCITEM-IGGCAS model.

We use the two-way coupled GCITEM-TIME3D model in this work. The following simulations are performed at September equinox for low $(\mathrm{F} 107, \mathrm{~F} 107 \mathrm{~A}=70)$ or high $(\mathrm{F} 107, \mathrm{~F} 107 \mathrm{~A}=210)$ solar activity levels and geomagnetic quiet input with a cross cap potential of $20 \mathrm{kV}$ and auroral particle precipitation with a hemispheric power of $10 \mathrm{GW}$. An IGRF geomagnetic field is used in these simulations. The initial conditions are from the MSIS00 and IRI2000 empirical models. The zonal mean states of neutral temperature/compositions from MSIS00 empirical model and the neutral temperature and density tides from TIMED/SABER observations are used at the low boundary (90-km altitude). These tides include the migrating diurnal tide, migrating semidiurnal tide, and non-migrating DE3 tide. The details of calculations of these tides from
TIMED/SABER observations can be seen in Ren et al. (2011b) and Wan et al. (2012). However, to analyze the influence of DE3 tide on the equinoctial asymmetry, we will use DE3 tide at March equinox instead of that at September equinox in some simulations. To keep removing all the effect of the initial conditions, 15-model-day runs were made to obtain the presented results in all simulations.

\section{Result and discussions}

To validate our simulation, Figure 1 shows the altitudinal and latitudinal variations of amplitude of the DE3 density tides from the model driven by September or March DE3 boundary and for different solar flux levels, which are all in a unit of \%. As shown in this figure, the maximum amplitudes of DE3 density tide all appear near equator and near the height of $100 \mathrm{~km}$. The amplitude of DE3 tide driven by September boundary is larger than that for March. Although DE3 tide in the mesospherelower thermosphere (MLT) region nearly does not vary with solar flux level, the amplitude of DE3 density tides at higher thermosphere (higher than $150 \mathrm{~km}$ ) for low solar flux level is stronger than that for high solar flux level. Because these simulated results agree well with the observed DE3 tide from TIMED and CHAMP measurements (see Oberheide et al. 2009), our simulations are credible.

Because we mainly pay attention to the influence of DE3 tide on the ionospheric zonal mean states, we will mainly analyze the longitudinal and diurnal mean (zonal mean) states of ionosphere. The distributions of ionospheric (a) $\rho_{\mathrm{DE} 3}$ September for low solar activity level $(\%)$

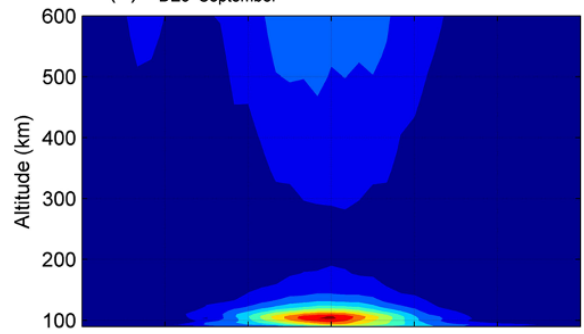

(c) $\rho_{\text {DE3 March }}$ for low solar activity level (\%)

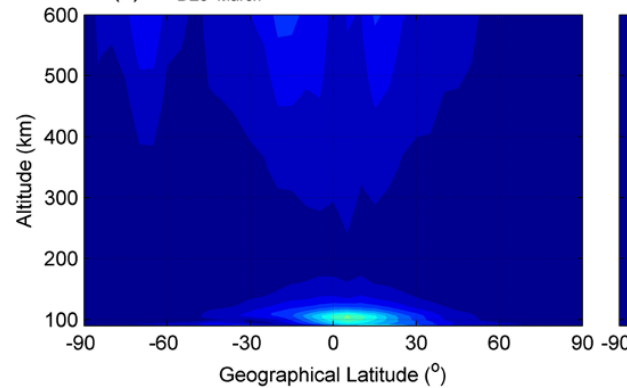

(b) $\rho_{\mathrm{DE} 3}$ September for high solar activity level (\%)

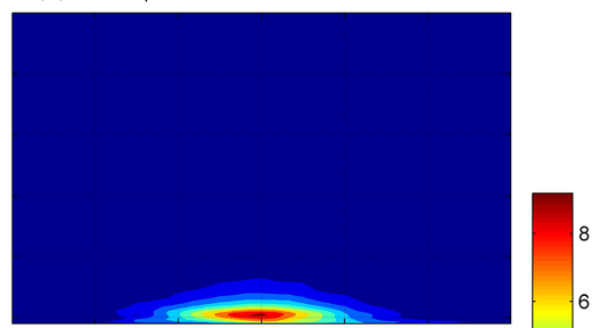

(d) $\rho_{\mathrm{DE} 3}$ March for high solar activity level (\%)

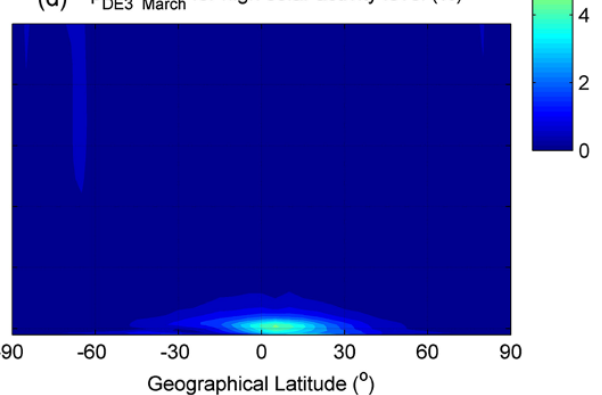

Figure 1 The altitudinal and latitudinal variations of amplitude of the DE3 density tides in a unit of \%. The left and right plots respectively show the DE3 tide for $(\mathbf{a}, \mathbf{c})$ low and $(\mathbf{b}, \mathbf{d})$ high solar flux levels. The top and bottom plots respectively show the DE3 tide drive by (a, b) September and (c, d) March DE3 boundaries. 
plasma density depend on the geomagnetic field, and the geomagnetic latitude varies with geographic longitude. Thus, we calculate the ionospheric mean states in the quasi-dipole coordinate (see Richmond 1995 for details).

Figure 2a,b respectively shows the latitudinal and altitudinal variations of the zonal mean of the ionospheric electron densities with different DE3 tides at September for low solar activity levels. We can notice that the electron densities in Figure 2a,b shows similar latitudinal and altitudinal variations, and their differences are weak. With the effect of the 'fountain effect', the equatorial ionization anomaly (EIA) appears in the mean electron densities, and the low-latitude ionosphere is higher than the mid- and high-latitude ionospheres. The relative difference between two cases is calculated as

$$
\delta N e=\frac{N e_{\mathrm{MarchDE} 3}-N e_{\mathrm{SeptemberDE3}}}{N e_{\text {SeptemberDE3 }}} \times 100 \%
$$

Figure $2 \mathrm{c}$ shows the latitudinal and altitudinal variations of $\delta \mathrm{Ne}$, and the solid lines in this figure represent the zero lines. Because most of the inputs and boundary conditions of these two simulations are the same as each other, $\delta N e$ must be driven by the equinoctial asymmetry in DE3 tide and expresses the influence of DE3 tide on the equinoctial asymmetry of the zonal mean ionospheric electron density. As shown in Figure 2c, the value of $\delta \mathrm{Ne}$ is mainly between $-2 \%$ and $3 \%$, and this asymmetry shows obvious latitudinal and altitudinal variations. We first focus on the altitudinal variation of $\delta \mathrm{Ne}$. At lower altitude (below about
$170 \mathrm{~km}), \delta \mathrm{Ne}$ is mainly less than zero, and the March DE3 tide decreases the zonal mean electron density. At higher altitude, $\delta \mathrm{Ne}$ is mainly larger than zero, and the March DE3 tide increases the zonal mean electron density. Figure $2 \mathrm{~d}$ shows the altitudinal profiles of the latitudinal mean $\delta \mathrm{Ne}$ (solid line), $\delta \mathrm{Ne}$ at $0^{\circ}$ (dashed line), $\delta \mathrm{Ne}$ at $15^{\circ}$ (EIA region, star line), and $\delta \mathrm{Ne}$ at $45^{\circ}$ (middle latitude, cycle line). Although four profiles show similar altitudinal variations in the MLT region, the altitudinal variations show large difference at higher altitude. The latitudinal mean $\delta \mathrm{Ne}$ profile shows the global mean ionospheric response to DE3 tide, and its altitudinal variation is more consistent with the profile at middle latitude. The minimum of latitudinal mean $\delta N e$ appears at about $93 \mathrm{~km}$. Then, $\delta N e$ increases with altitude and shows a peak near $130 \mathrm{~km}$. Above $130 \mathrm{~km}, \delta N e$ begins to decrease with altitude again and shows the second minimum near $160 \mathrm{~km}$. Above $160 \mathrm{~km}, \delta \mathrm{Ne}$ begins to increase with altitude again and shows a peak near $265 \mathrm{~km}$. Above $265 \mathrm{~km}, \delta \mathrm{Ne}$ keeps decreasing with altitude.

Except the altitudinal variations, $\delta \mathrm{Ne}$ also shows complex latitudinal variations. However, the latitudinal variations also vary with altitude. At lower altitude, the latitudinal variations are not significant, and the altitudinal variations are much stronger than the latitudinal variations. The ions at low ionosphere are main molecular ions, and the plasma densities are controlled by photochemistry. Hence, the low ionospheric latitudinal variations are mainly controlled by a latitudinal variation of sun zenith angle, and the latitudinal variations of $\delta \mathrm{Ne}$ are not significant. However, we (a) Electron density with September DE3 $\left(10^{11} / \mathrm{m}^{-3}\right)$

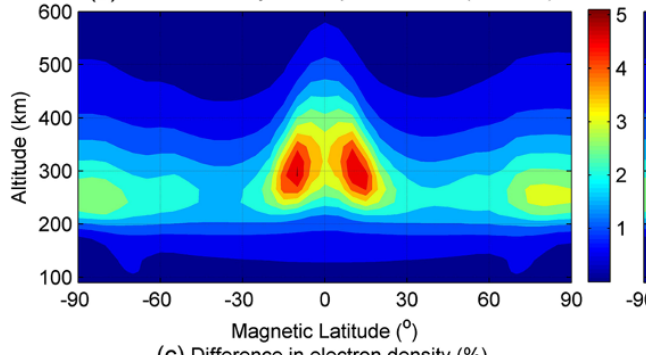

(c) Difference in electron density (\%)

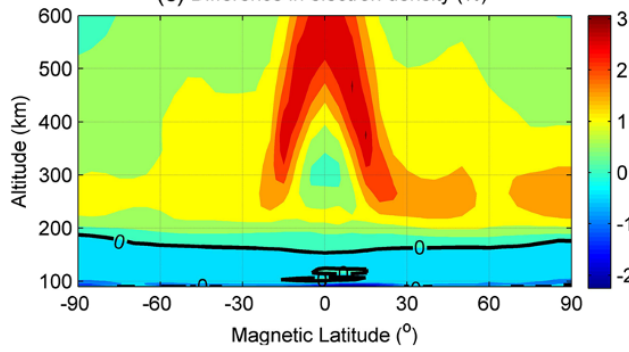

(b) Electron density with March DE3 $\left(10^{11} / \mathrm{m}^{-3}\right)$

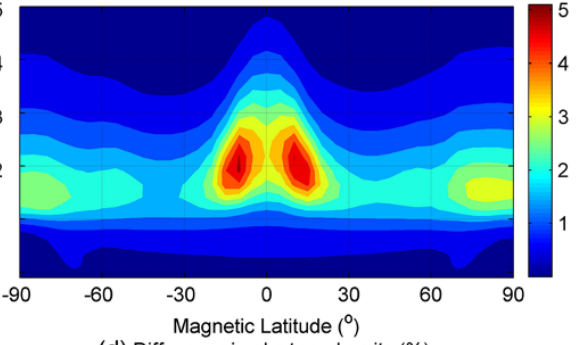

(d) Difference in electron density (\%)

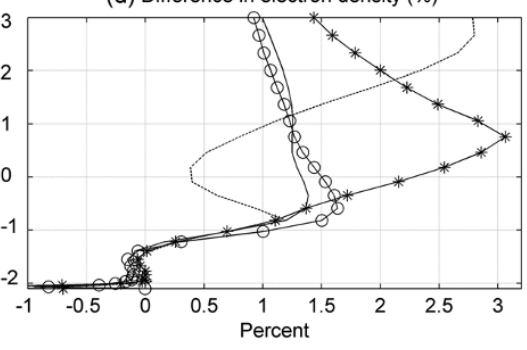

Figure 2 The altitudinal and latitudinal variations of the simulated zonal mean electron densities. The altitudinal and latitudinal variations of the simulated zonal mean electron densities at September driven by (a) September DE3 tide (in a unit of $10^{11} / \mathrm{m}^{-3}$ ) and driven by (b) March DE3 tide (in a unit of $10^{11} / \mathrm{m}^{-3}$ ); the relative difference of the zonal mean electron densities between (c) two simulations ( $\delta \mathrm{Ne}$ ) (in a unit of \%) and the (d) altitudinal profiles of $\delta \mathrm{Ne}$ (in a unit of \%). The solid lines in (c) represent the zero lines. 
can notice that there are two small scale structures near the equator. The amplitude of DE3 density tides should show its maximum near the equator, and these two small scale structures may be driven by the vertical propagation of the DE3 tide, which is stronger near the geographic equator. Lindzen (1967) suggested that diurnal tides can break down in the MLT region, generate turbulence, enhance the eddy mixing, and change the chemical compositions in that region and in higher thermosphere. Because diurnal tides can affect the eddy mixing and change the chemical compositions in the MLT region, DE3 tide can change the $\mathrm{NO}$ and $\mathrm{O}_{2}$ densities in E-region and affect the E-region molecular ion (and electron) density (see Ren et al. 2012b). Because the ionospheric dynamics play a more important role at higher ionosphere than at lower ionosphere, the altitudinal and latitudinal variations of $\delta \mathrm{Ne}$ at the higher ionosphere are more complex than those at the lower ionosphere. Different from the lower ionosphere, the latitudinal variations at higher ionosphere are significant, and $\delta \mathrm{Ne}$ at low-latitude and at mid- and highlatitudes shows different features, which may be driven by different mechanisms. At mid- and high-latitudes, there are obvious latitudinal variations and south-north asymmetry. However, $\delta \mathrm{Ne}$ at mid- and high-latitudes are mainly positive. Although the dynamic mechanism can affect the ionospheric electron density, it mainly transports the ion and electron, and its influence on the total electron density is weak. Hence, although the dynamic mechanisms may play important roles in driving the $\delta \mathrm{Ne}$ at mid- and highlatitudes, the zonal mean $\delta \mathrm{Ne}$ at mid- and high-latitudes may mainly be controlled by the chemical mechanisms. As discussed above, DE3 tides that enhance the eddy diffusions can cause the enhanced downward transport of atomic oxygen and upward transport of $\mathrm{O}_{2}$ and $\mathrm{N}_{2}$, change the chemical compositions in high thermosphere, and affect the F-region ionospheric chemical mechanisms. Different from $\delta \mathrm{Ne}$ at mid- and high-latitudes which are mainly positive, $\delta \mathrm{Ne}$ near the equator appears negative around the height of $300 \mathrm{~km}$, and a positive area with a higher value appears around this negative area. Actually, we can say that EIA also appears in $\delta N e$, and this structure must be driven by the 'fountain effect' and upward equatorial vertical $\mathrm{E} \times \mathrm{B}$ plasma drifts. Previous research suggested that DE3 tide can affect the ionospheric dynamo and drive WN4 in vertical drifts (e.g., Kil et al. 2007; Ren et al. 2009a, 2010; Jin et al. 2008). Although the zonal mean of WN4 in vertical drifts should be zero, our simulations suggested that DE3 tide also affects the longitudinal mean states of vertical $\mathrm{E} \times \mathrm{B}$ plasma drifts and of the EIA structure in plasma density. Because the zonal electric fields' line integrals along the dip equator must be zero (curl-free condition), the zonal mean states of vertical $\mathrm{E} \times$ $B$ plasma drifts should also nearly equal to zero. Hence, we analyze the longitudinal averaged diurnal variation of the vertical drift at dip equator and its asymmetry driven by DE3 tide instead of that of zonal mean states. The solid lines in Figure 3a,b respectively shows the longitudinal averaged diurnal variation of the vertical drift at dip equator at the height of $320 \mathrm{~km}$ for low solar flux level and the vertical drift asymmetry $\left(\mathrm{V}_{\text {March }}-\mathrm{V}_{\text {September }}\right)$ driven by DE3 (a) Longitudinal average vertical drift ( $\mathrm{m} / \mathrm{s})$

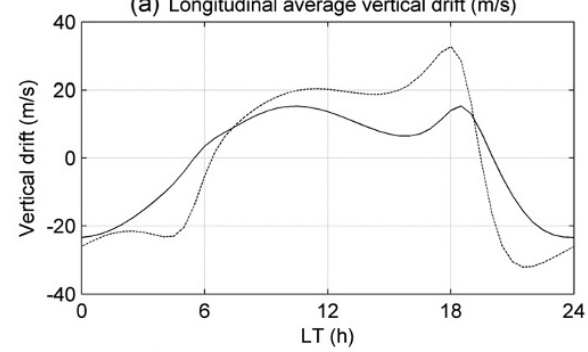

(c) Difference for low solar activity (\%)

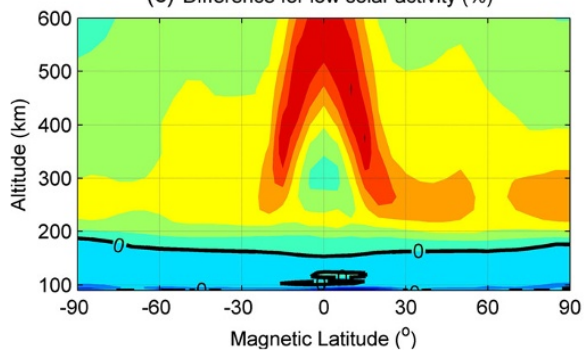

(b) Drift asymmetry $(\mathrm{m} / \mathrm{s})$

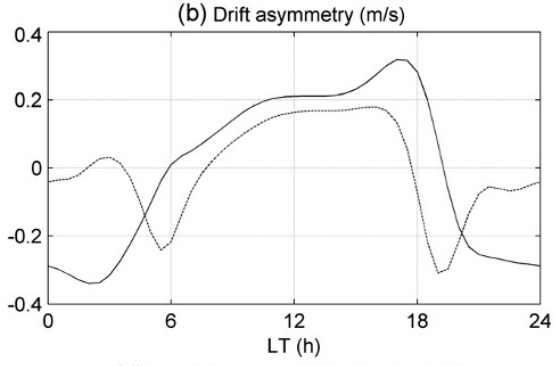

(d) Difference for high solar activity (\%)

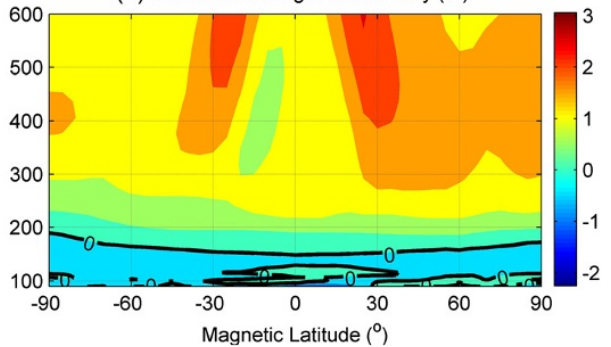

Figure 3 Longitudinal averaged diurnal variation, drift asymmetry, and altitudinal and latitudinal variations of the relative difference. The top plots show the longitudinal averaged diurnal variation of the vertical drift at dip equator at the height of $320 \mathrm{~km}$ (a) and the vertical drift asymmetry driven by DE3 tide (b). The solid and dashed lines represent low and high solar flux levels, respectively. The bottom plots show the altitudinal and latitudinal variations of the relative difference of the zonal mean electron densities for low solar activity level (c) and for high solar activity level (d). The solid lines in $(\mathbf{c}, \mathbf{d})$ represent the zero lines. 
tide. As shown in these figures, the diurnal variations of the vertical drift agree with the vertical drift observation from satellite and from Jicamacar incoherent scatter radar, and the drift and drift asymmetry are both mainly upward during daytime and downward at night. Although the drift asymmetry is obviously smaller than the drift, the DE3 tide still enhances the 'fountain effect' and causes above lowlatitude ionospheric asymmetry structure.

Previous research implied that the ionospheric equinoctial asymmetry may vary with solar activity level, and Wan et al. $(2008,2012)$ also suggested that the ionospheric WN4 varies with solar activity level. Hence, we also compare $\delta \mathrm{Ne}$ at high solar activity level with that at low solar activity level. Figure 3c,d respectively shows the latitudinal and altitudinal variations of the zonal mean ionospheric electron densities for low solar activity level and for high solar activity level, and the dashed lines in Figure 3a,b respectively shows the longitudinal averaged diurnal variation of the vertical drift at dip equator at the height of $320 \mathrm{~km}$ for low solar flux level and the vertical drift asymmetry driven by DE3 tide. The solid lines in Figure 3c,d represent the zero lines. At lower ionosphere, $\delta \mathrm{Ne}$ at high solar activity level is mainly larger than that at low solar activity level, and the equinoctial asymmetry driven by DE3 tide decreases with the increase of solar activity. At higher mid- and high-latitude ionospheres, although $\delta N e$ at high solar activity level also is mainly larger than that at low solar activity level, the equinoctial asymmetry driven by DE3 tide mainly increases with the increase of solar activity. At low-latitude ionosphere, the EIA structure also appears in the $\delta N e$ at high solar activity level. Because the equator daytime upward drift for high solar flux level is stronger than that for low solar flux level, the spatial scale of EIA is larger than that at low solar activity level. However, because the daytime drift asymmetry for high solar flux level is weaker than that for low solar flux level, EIA of $\delta \mathrm{Ne}$ at high solar activity level is obviously weaker than that at low solar activity level, and the EIA structure in equinoctial asymmetry mainly decreases with the increase of solar activity.

\section{Summary and conclusion}

In this paper, we simulate the influence of DE3 tide on the equinoctial asymmetry of the zonal mean states of ionospheric electron density with the GCITEM-IGGCAS model. Through respectively adding September DE3 tide and March DE3 tide at the low boundary, we simulate the distribution of ionospheric electron density and calculate the relative difference in zonal mean electron density. The influence of DE3 tide on the equinoctial asymmetry of the zonal mean electron density varies with latitude, altitude, and solar activity level. Compared with the density driven by the September DE3 tide, the March DE3 tide mainly decreases the lower ionospheric zonal mean electron density and mainly increases the electron density at higher ionosphere. In the low-latitude ionosphere, DE3 tide drives an EIA structure at higher ionosphere in the relative difference of zonal mean electron density, which may imply that DE3 tide affects the zonal mean equatorial vertical $\mathrm{E} \times \mathrm{B}$ plasma drifts. Although the lower ionospheric equinoctial asymmetry driven by DE3 tide mainly decreases with the increase of solar activity, the asymmetry at higher ionosphere mainly increases with solar activity. However, EIA in equinoctial asymmetry mainly decreases with the increase of solar activity.

\section{Competing interests}

The authors declare that they have no competing interests.

\section{Authors' contributions}

ZR designed this study, carried out simulations, and analyzed the simulated results. WW participated in the design of the study and the analysis of the simulated results. JX calculated DE3 tides from TIMED/SABER observation. $\mathrm{LL}$ participated in the analysis of the simulated results. All authors read and approved the final manuscript.

\section{Acknowledgements}

This work is supported by the Chinese Academy of Sciences (KZZD-EW-01-2), National Important Basic Research Project (2011CB811405), National Science Foundation of China $(41474133,41322030,41321003,41131066)$, and Youth Innovation Promotion Association, CAS.

Received: 29 March 2014 Accepted: 4 September 2014

Published: 17 September 2014

\section{References}

Adebesin B, Adeniyi J, AAdimula I, Reinisch B (2013) Equatorial vertical plasma drift velocities and electron densities inferred from ground-based ionosonde measurements during low solar activity. J Atmos Sol Terr Phys 97:58-64

Aruliah AL, Farmer AD, Fuller-Rowell TJ, Wild MN, Hapgood M, Rees D (1996) An equinoctial asymmetry in the high-latitude thermosphere and ionosphere. J Geophys Res 101(A7):15713-15722

Bailey GJ, Su YZ, Oyama K-I (2000) Yearly variations in the low-latitude topside ionosphere. Ann Geophys 18:789-798

Balan N, Otsuka Y, Fukao S, Bailey GJ (1998) Equinoctial asymmetries in the ionosphere and thermosphere observed by the MU radar, J. Geophys Res 103(A5):9481-9486

Balan N, Kawamura S, Nakamura T, Yamamoto M, Fukao S, Oliver WL, Hagan ME, Aylward AD, Alleyne $H$ (2006) Simultaneous mesosphere-lower thermosphere and thermospheric $\mathrm{F}$ region observations using middle and upper atmosphere radar. J Geophys Res 111:A10S17, doi:10.1029/2005JA011487

Brahmanandam PS, Uma G, Liu JY, Chu YH, Latha Devi NSMP, Kakinami Y (2012) Global S4 index variations observed using FORMOSAT-3/COSMIC GPS RO technique during a solar minimum year. J Geophys Res 117:A09322

Chen Y, Liu L, Wan W, Ren Z (2012) Equinoctial asymmetry in solar activity variations of NmF2 and TEC. Ann Geophys 30:613-622

Forbes JM, Roble RG, Fesen C (1993) Acceleration, heating, and compositional mixing of the thermosphere due to upward propagating tides. J Geophys Res 98(A1):311-321

Forbes JM, Zhang X, Palo S, Russell J, Mertens CJ, Mlynczak M (2008) Tidal variability in the ionospheric dynamo region. J Geophys Res 113:A02310, doi:10.1029/2007JA012737

Jin H, Miyoshi Y, Fujiwara H, Shinagawa $H$ (2008) Electrodynamics of the formation of ionospheric wave number4 longitudinal structure. J Geophys Res 113:A09307, doi:10.1029/2008JA013301

Jones M Jr, Forbes JM, Hagan ME, Maute A (2014) Impacts of vertically propagating tides on the mean state of the ionosphere-thermosphere system. J Geophys Res 119:2197-2213, doi:10.1002/2013JA019744

Kawamura S, Balan N, Otsuka Y, Fukao S (2002) Annual and semiannual variations of the midlatitude ionosphere under low solar activity. J Geophys Res 107(A8):1166, doi:10.1029/2001JA000267 
Kil H, Oh S-J, Kelley MC, Paxton L, England SL, Talaat E, Min K-W, Su S-Y (2007) Longitudinal structure of the vertical $E \times B$ drift and ion density seen from ROCSAT-1. Geophys Res Lett 34:L14110, doi:10.1029/2007GL030018

Lindzen RS (1967) Thermally driven diurnal tide in the atmosphere. Q J Roy Meteorol Soc 93(395):18-42

Liu L, He M, Yue X, Ning B, Wan W (2010) lonosphere around equinoxes during low solar activity. J Geophys Res 115:A09307, doi:10.1029/2010JA015318

Mukhtarov P, Pancheva D, Andonov B (2009) Global structure and seasonal and interannual variability of the migrating diurnal tide seen in the SABER/TIMED temperatures between 20 and 120 km. J Geophys Res 114:A02309, doi:10.1029/ 2008JA013759

Oberheide J, Forbes JM (2008) Tidal propagation of deep tropical cloud signatures into the thermosphere. Geophys Res Lett 35:L04816, doi:10.1029/2007GL032397

Oberheide J, Forbes JM, Hausler K, Wu Q, Bruinsma SL (2009) Tropospheric tides from 80 to $400 \mathrm{~km}$ : propagation, interannual variability, and solar cycle effects. J Geophys Res 114:D00I05, doi:10.1029/2009JD012388

Pancheva D, Mukhtarov P (2010) Strong evidence for the tidal control on the longitudinal structure of the ionospheric F-region. Geophys Res Lett 37:L14105, doi:10.1029/2010GL044039

Ren Z, Wan W, Wei Y, Liu L, Yu T (2008) A theoretical model for mid- and low-latitude ionospheric electric fields in realistic geomagnetic fields. Chin Sci Bull 53(24):3883-3890

Ren Z, Wan W, Liu L (2009a) GCITEM-IGGCAS: A new global coupled ionospherethermosphere-electrodynamics model. J Atmos Sol Terr Phys 71 (17\&18):2064-2076

Ren Z, Wan W, Liu L, Xiong J (2009b) Intra-annual variation of wave number 4 structure of vertical $E \times B$ drifts in the equatorial ionosphere seen from ROCSAT-1. J Geophys Res 114:A05308, doi:10.1029/2009JA014060

Ren Z, Wan W, Xiong J, Liu L (2010) Simulated wave number 4 structure in equatorial F-region vertical plasma drifts. J Geophys Res 115:A05301, doi:10.1029/2009JA014746

Ren Z, Wan W, Liu L, Chen Y, Le H (2011a) Equinoctial asymmetry of ionospheric vertical plasma drifts and its effect on F-region plasma density. J Geophys Res 116:A02308, doi:10.1029/2010JA016081

Ren Z, Wan W, Liu L, Xiong J (2011b) Simulated longitudinal variations in the lower thermospheric nitric oxide induced by nonmigrating tides. J Geophys Res 116:A04301, doi:10.1029/2010JA016131

Ren Z, Wan W, Liu L, Le H (2012a) TIME3D-IGGCAS: A new three-dimension mid- and low-latitude theoretical ionospheric model in realistic geomagnetic fields. J Atmos Sol Terr Phys 80:258-266

Ren Z, Wan W, Liu L, Xiong J (2012b) Simulated longitudinal variations in the E-region plasma density induced by non-migrating tides. J Atmos Sol Ter Phys 90:68-76

Ren Z, Wan W, Xiong J, Liu L (2012c) Simulated equinoctial asymmetry of the ionospheric vertical plasma drifts. J Geophys Res 117:A01301, doi:10.1029/2011JA016952

Richmond AD (1995) lonospheric electrodynamics using magnetic apex coordinates. J Geomagn Geoelectr 47(1):191-212

Sripathi S, Kakad B, Bhattacharyya A (2011) Study of equinoctial asymmetry in the equatorial spread $\mathrm{F}$ (ESF) irregularities over Indian region using multiinstrument observations in the descending phase of solar cycle 23. J Geophys Res 116:A11302, doi:10.1029/2011JA016625

Titheridge JE (1973) The electron content of the southern mid-latitude ionosphere, 1965-1971. J Atmos Terr Phys 35:981-1001

Titheridge JE, Buonsanto MJ (1983) Annual variations in the electron content and height of the $\mathrm{F}$ layer in the Northern and Southern hemispheres, related to neutral composition. J Atmos Terr Phys 45:683-696

Unnikrishnan K, Nair RB, Venugopal C (2002) Harmonic analysis and an empirical model for TEC over Palehua. J Atmos Solar-Terr Phys 64:1833-1840

Wan W, Liu L, Pi X, Zhang M-L, Ning B, Xiong J, Ding F (2008) Wavenumber-four patterns of the total electron content over the low latitude ionosphere. Geophys Res Lett 35:L12104, doi:10.1029/2008GL033755

Wan W, Xiong J, Ren Z, Liu L, Zhang M-L, Ding F, Ning B, Zhao B, Yue X (2010) Correlation between the ionospheric WN4 signature and the upper atmospheric DE3 tide. J Geophys Res 115:A11303, doi:10.1029/2010JA015527

Wan W, Ren Z, Ding F, Xiong J, Liu L, Ning B, Zhao B, Li G, Zhang M-L (2012) A simulation study for the couplings between DE3 tide and longitudinal WN4 structure in the thermosphere and ionosphere. J Atmos Sol Terr Phys 90:52-60
Wu Q, Ortland DA, Foster B, Roble RG (2012) Simulation of nonmigrating tide influences on the thermosphere and ionosphere with a TIMED data driven TIEGCM. J Atmos Sol Terr Phys 90:61-67

Zhang S-R, Holt JM, Zalucha AM, Amory-Mazaudier C (2004) Midlatitude ionospheric plasma temperature climatology and empirical model based on Saint Santin incoherent scatter radar data from 1966 to 1987. J Geophys Res 109:A11311, doi:10.1029/2004JA010709

Zhao B, Wan W, Liu L, Mao T, Ren Z, Wang M, Christensen AB (2007) Features of annual and semiannual variations derived from the global ionospheric maps of total electron content. Ann Geophys 25:2513-2527

\section{doi:10.1186/1880-5981-66-117}

Cite this article as: Ren et al:: Influence of DE3 tide on the equinoctial asymmetry of the zonal mean ionospheric electron density. Earth, Planets and Space 2014 66:117.

\section{Submit your manuscript to a SpringerOpen ${ }^{\odot}$ journal and benefit from:}

- Convenient online submission

- Rigorous peer review

- Immediate publication on acceptance

- Open access: articles freely available online

- High visibility within the field

- Retaining the copyright to your article

Submit your next manuscript at $>$ springeropen.com 